\title{
QUALIDADE DE VIDA NO TRABALHO DOCENTE: UM ESTUDO DE CASO EM UMA INSTITUIÇÃO DE ENSINO SUPERIOR
}

\author{
Patricio Henrique de Vasconcelos \\ Mestrando do Programa de Pós Graduação em Engenharia de Produção da Universidade Tecnológica \\ Federal do Paraná - UTFPR \\ Professor Assistente do Centro de Ensino Superior de Campos Gerais - CESCAGE \\ adm.patricio@yahoo.com.br
}

\section{Carlos Eduardo Leitão Alves}

Graduação em Administração de Empresas pela Faculdade Santa Cruz - FUNADESP carlosadm20@hotmail.com

\section{Suenya Freire do Monte Santos}

Doutoranda em Administração pela Universidad Internacional Tres Fronteras - UNINTER

Professora da Faculdade Mauricio de Nassau - UNINASSAU

suenya.freire@gmail.com

\section{Antonio Carlos de Francisco}

Doutorado em Engenharia de Produção pela Universidade Federal de Santa Catarina - UFSC Professor de Ensino Básico, Técnico e Tecnológico da Universidade Tecnológica Federal do Paraná UTFPR acfrancisco@gmail.com

\section{RESUMO}

Em um mundo cada vez mais competitivo e globalizado, as organizações têm nas pessoas o seu maior diferencial. Surge então a vontade dos funcionários de terem a qualidade de vida no trabalho, com o interesse em obter melhor desempenho organizacional. Esta pesquisa teve como objetivo analisar os aspectos referentes à Qualidade de Vida no Trabalho do corpo docente do Centro de Ensino Superior Santa Cruz (CESAC), mantenedora da Faculdade Santa Cruz (FACRUZ) e do Instituto Superior de Educação (ISED), de Santa Cruz do Capibaribe (PE). O modelo teórico escolhido para o estudo foi o de avaliação de Qualidade de Vida no Trabalho, de Richard Walton, composto de oito critérios, cada um com seus respectivos indicadores. Para cada um dos critérios do modelo, a pesquisa buscou observar se as questões se relacionavam com os desejos e expectativas dos colaboradores. Quanto à metodologia utilizada, optou-se por uma pesquisa exploratória e descritiva. O instrumento de coleta de dados foi um questionário estruturado, que foi aplicado aos professores da empresa. Em questão observou-se que o nível de satisfação dos funcionários é alto, o que demonstra existência dos indicadores da Qualidade de Vida no Trabalho da empresa.

Palavras-chave: Qualidade de Vida no Trabalho; Desempenho; Satisfação. 


\section{INTRODUÇÃO}

Todas as organizações são compostas por pessoas e dependem destas para alcançar seus objetivos. Esses indivíduos, denominados de funcionários/colaboradores, passam a maior parte do seu tempo exercendo atividades dentro de organizações e veem nestas o meio pelo qual alcançam seus objetivos pessoais. Portanto, ambos estão envolvidos em uma complexa e contínua interação.

Quando as pessoas passaram a assumir maior importância nas empresas, percebeu-se que houve uma mudança em termos de conceitos e práticas gerenciais, em especial no tocante a gestão de pessoas. Acredita-se que não é mais admissível que os administradores visualizem as pessoas como recursos produtivos ou meros agentes passivos. A tendência que se nota nas organizações bemsucedidas é que em vez de investirem diretamente nos produtos ou serviços oferecidos elas têm investido nas pessoas que os desenvolvem, criam e produzem.

As primeiras preocupações teóricas e práticas na área de qualidade envolviam basicamente a questão da qualidade do produto objetivando satisfazer a necessidade do cliente externo. No entanto, com o decorrer do tempo percebeu-se que não se pode falar em qualidade de produtos e serviços se aqueles que vão produzi-los não têm qualidade de vida no trabalho (QVT).

Ademais, as transformações sofridas pela sociedade gerou novos valores demandados pela qualidade, qualidade de vida e QVT. Sendo assim, o homem passa a ser visto como a peça mais importante do sistema produtivo e da prestação de serviços, daí a preocupação com a QVT, sendo um tema de grande importância visto que empresas estão começando a adotar métodos que proporcionam maior bem-estar entre seus trabalhadores.

Ao pôr em pratica os conhecimentos sobre esse tema, empresas percebem um aumento significativo de benefícios para a organização, assim também como na vida de seus empregados. Esses benefícios incluem: redução da rotatividade, menor absenteísmo, aumento da produtividade, redução da fadiga, atitude favorável no trabalho, satisfação no trabalho, desenvolvimento da saúde e segurança, entre outros.

Existem vários modelos para avaliação da qualidade de vida no trabalho, um dos mais conhecidos na comunidade científica é o modelo proposto por Walton (1974), que é composto por oito critérios, com indicadores que afetam as pessoas em seu trabalho. Essa ferramenta permite aos gestores das organizações disporem de um diagnóstico sobre a QVT interna e, a partir deste, tomar as ações cabíveis para melhorar as condições de trabalho.

O presente artigo é fruto da aplicação do modelo de Walton (1974) junto aos funcionários de uma instituição privada de ensino superior, situada no estado de Pernambuco. O objetivo do estudo foi 
identificar a existência dos indicadores de QVT na percepção dos docentes dessa instuição de ensino superior; traçar um perfil desses docentes verificando a existência de aspectos que influenciam na satisfação deles e ao final sugerir melhorias na QVT da empresa estudada a partir das informações obtidas neste estudo.

A escolha desse modelo justifica-se pela amplitude de seus critérios para o estudo da QVT, pois, além de enfatizar questões elementares para a sua realização permite a identificação de variáveis como: fatores higiênicos, aspectos relacionados a condições físicas, segurança e remuneração, considera, também, elementos citados por outros estudiosos.

O trabalho desenvolvido é voltado para demonstrar e despertar a necessidade de se preocupar com o ambiente de trabalho mostrando a importância da qualidade de vida no trabalho como pressuposto para a sobrevivência, satisfação e melhoria contínua das empresas.

\section{FUNDAMENTAÇÃO TEÓRICA}

\subsection{Gestão de Pessoas}

$\mathrm{Na}$ atual conjuntura de mercado tem-se como pilar fundamental a informação e como elemento-chave, as pessoas. Esses dois elementos conjuntamente contribuem para o alcance dos objetivos de qualquer organização. Não existem empresas sem pessoas, e estas contribuem para que as organizações possam atingir seus objetivos de maneira eficiente e eficaz, ou seja, alcançando a excelência.

Aumentou o número de empresas no mercado, principalmente no setor de serviços, acarretando necessidades de trabalho humano especializado e motivado. Segundo Chiavenato (2004):

O crescimento acarreta maior complexidade dos recursos necessários às suas operações, com o aumento de capital, incremento da tecnologia, atividades de apoio e etc. E, de lambuja, provoca o aumento do número de pessoas, bem como a necessidade de se intensificar a aplicação de seus conhecimentos, habilidades, e destrezas indispensáveis à manutenção e competitividade do negócio [...] E as pessoas passam a significar o diferencial competitivo que mantêm e promove o sucesso organizacional (p. 04).

Com isso vê-se a importância da gestão de pessoas que para Gil (2001a, p. 17) "é a função gerencial que visa a cooperação das pessoas que atuam nas organizações para o alcance dos objetivos tanto organizacionais quanto individuais".

Revista de Administração e Inovação, São Paulo, v. 9, n. 2, p. 79-97, abril/jun. 2012. 
Administrar pessoas é um trabalho que envolve muitas dificuldades. De acordo com Chiavenato (2004):

é uma área muito sensível ... É contingencial e situacional, pois depende de vários aspectos, como a cultura que existe em cada organização, da estrutura organizacional adotada, das características do contexto ambiental, do negócio da organização, da tecnologia utilizada, dos processos internos e de uma infinidade de outras variáveis importantes (p. 06).

Uma das contribuições primordiais da moderna gestão de pessoas é a possibilidade de perceber os colaboradores internos de uma organização como seres humanos dotados de necessidades. Chiavenato (2002) nos diz que:

Em recursos humanos tem duas alternativas: considerar pessoas como pessoas (dotadas de características próprias de personalidade e de individualidade, operações, valores, atitudes, motivações e objetivos individuais) ou considerar pessoas como recursos (dotadas de habilidades, capacidades, destrezas, conhecimentos e competências necessárias para a tarefa organizacional) (p. 80).

As pessoas são o principal elemento de qualquer empresa e devem ser vistas em duas dimensões: a humana e a instrumental, por isso existe a grande importância da gestão de pessoas para dar suporte, provendo os fatores que geram os estados de satisfação e insatisfação.

Assim sendo, a Gestão de Pessoas baseia-se em três aspectos fundamentais: as pessoas como seres humanos, e não meros recursos; as pessoas como atividades inteligentes de recursos organizacionais; as pessoas como parceiros da organização.

\subsubsection{Da administração de recursos humanos a gestão de pessoas}

Tratar pessoas como meros recursos é uma visão tradicionalista e limitada do homem organizacional representada pelo paradigma da administração de recursos humanos. Quando se fala em Gestão de Pessoas em vez de Administração de Recursos Humanos, percebe-se a existência de um novo olhar dos gestores sob as pessoas e sua importância para as empresas.

Tendo em vista que nem sempre foi assim, antes as pessoas eram vistas como recursos, o que mudou através dos tempos e se exemplifica em três eras, a da Industrialização Clássica, a era da Industrialização Neoclássica e a era da Informação.

a) Era da Industrialização Clássica: iniciada após a Revolução Industrial até a metade do século XIX adotou-se nas organizações uma estrutura mais burocrática, onde tudo era voltado para a ênfase da eficiência da produção, não existiam estímulos para mudança e inovação, as pessoas eram tratadas como recursos de produção, tinham o valor de uma máquina;

Revista de Administração e Inovação, São Paulo, v. 9, n. 2, p. 79-97, abril/jun. 2012. 
b) Era da Industrialização Neoclássica: período que corresponde entre as décadas de 1950 e 1990 , em que houve uma crescente mudança no mercado, que passou a ser bem mais competitivo. $\mathrm{O}$ modelo burocrático não resistiria a tais avanços mercadológicos, sendo substituído por modelos que utilizariam a prática da inovação e mudanças externas. Em consequência disso, segundo Gil (2001b, p. 20), "as empresas passaram a preocupar-se mais com as condições de trabalho".

c) Era da Informação: teve início na década de 1990 e se estende até a atualidade. Diz Chiavenato (2004, p. 37): “A principal característica dessa era são as mudanças que se tornaram rápidas, imprevistas, turbulentas e inesperadas".

A informação e a capacidade de comunicação tornou-se essencial a qualquer empresa, deu-se início à globalização, a economia transformou-se de internacional para mundial. Tendo informação ou pessoas informadas e capacitadas, empresas transformam dados em oportunidades, ideias, fortificam suas estruturas e tendem a ganhar mercado. Houve uma grande mudança de paradigma sendo o termo RH substituído por Gestão de Pessoas.

\subsubsection{O que é Gestão de Pessoas}

Para Gil (2001b), Gestão de Pessoas é o processo de suprimento, aplicação, desenvolvimento e monitoração das pessoas. Chiavenato (2004, p. 10) diz que "gestão de pessoas é a função que permite a colaboração eficaz das pessoas e empregados, funcionários, recursos humanos, talentos ou qualquer denominação utilizada para alcançar os objetivos organizacionais e individuais".

A gestão de pessoas tem como objetivos encontrar, atrair e manter as pessoas de que a organização necessita. No entanto, conforme nos apresenta Chiavenato (2004), para que seja eficaz deve-se passar por seis processos, que são: agregar pessoas; aplicar pessoas; recompensá-las; desenvolver pessoas; manter pessoas e monitorar pessoas.

\subsubsection{Processo de Gestão de Pessoas}

a) Agregar Pessoas: obtenção de novas pessoas para trabalhar nas empresas, que é feita através de recrutamento e seleção.

b) Aplicar Pessoas: estruturar o que elas vão fazer nas empresas, a que setor elas servirão, sempre orientando seu desenvolvimento.

c) Recompensar Pessoas: processo de incentivar pessoas para que elas alcancem seus objetivos pessoais, estimulando o comportamento dos colaboradores, fazendo-os melhorar seu desempenho. A recompensa pode ser através da higiene e da segurança do trabalho e da 
política salarial, que, quando bem administradas, proporcionam uma adequada QVT aos colaboradores. Além de benefícios extrassalariais que podem ser dados aos clientes internos. Existe também a importância da motivação, do feedback, para estimular as pessoas a procurarem trabalhar com mais qualidade e dedicação.

d) Desenvolver Pessoas: são os processos de capacitação das pessoas para alavancar o desenvolvimento profissional e pessoal. Chiavenato (2004) diz que o processo de desenvolver está ligado à educação, ao treinamento, que, segundo Gil (2001a, p. 12), "é o meio para adequar cada pessoa a seu cargo, com vista no alcance dos objetivos da organização".

e) Manter Pessoas: são os processos para criar condições para o trabalho dos colaboradores. De acordo com Gil (2001a), significa a qualidade de vida dos empregados que precisam ser felizes. Já Chiavenato (2004) diz que o processo de manter pessoas busca e proporciona motivação para o alcance de objetivos. Para que sejam produtivas, devem sentir que o trabalho que executam é adequado a suas habilidades e que são tratadas como pessoas.

f) Monitorar Pessoas: são os processos de analisar resultados e buscar melhoria contínua, de buscar medidas corretivas para não existir erros. Dar feedbacks para motivar os empregados fazendo-os trabalhar com mais eficiência. O importante é motivar sempre, segundo Castiglione (2006), motivação é a força que estimula a ação. Já Chiavenato (2004) diz que a motivação transforma o funcionário em parceiro e agente ativo da mudança e inovação.

\subsection{Qualidade}

\subsubsection{Conceito de Qualidade}

Definida por Araújo (2006) como a busca pela perfeição a fim de lidar com clientes cada vez mais conscientes das facilidades de consumo e da variedade de empresas a lhes oferecer produtos. A qualidade não está relacionada apenas à certificação do produto ou serviço, mas a todo esforço que a empresa faz para que o público-alvo a perceba no que produz ou realiza.

Moller (2002) nos mostra que existem cinco dimensões para melhorar a qualidade global da empresa, que são nas áreas da qualidade departamental, pessoal, de serviço, da empresa e do produto.

Falando-se em qualidade, deve-se evidenciar a existência da qualidade certificada que pode expressar-se através das normas ISO, International Organization for Standardization, uma organização internacional sem fins lucrativos criada em 1947, sediada em Genebra, responsável pela elaboração dos padrões internacionais de qualidade. Como resultado da integração das normas 
nasceram as ISO/9000 que são um conjunto de cinco normas para a gestão e certificação da qualidade dos produtos da empresa.

\subsubsection{Qualidade de Vida}

A qualidade de vida é um fator que todas as pessoas que trabalham buscam, e, além de buscarse a qualidade de vida no lado pessoal, vincula-se a qualidade de vida ao trabalho pelo fato de se passar a maior parte do tempo trabalhando em organizações, seja no próprio ambiente, seja na redução do estresse. Araújo (2006), diz que "atualmente, as organizações contam com novos recursos para promover a prática da saúde no ambiente de trabalho".

Rossi, Parrewé e Saunter (2007, p. 09) diz que "o stress organizacional na sociedade tornou-se um foco importante de preocupação". Então cabe ao administrador de empresas modificar esse fato, gerando ou proporcionando ao colaborador um serviço que satisfaça as necessidades do mesmo obtendo-se assim a QTV da empresa.

\subsubsection{Qualidade de Vida no Trabalho}

Rodrigues (2007) diz que o termo QVT surgiu na década de 70 pela mudança no enfoque do gerenciamento organizacional, e nessa década surgem os primeiros movimentos e aplicações estruturadas e sistematizadas no interior da organização, utilizando essa ferramenta. Tratando-se do processo de evolução da QVT, pode-se citar as escolas de pensamento, a saber: a escola socioeconômica, a escola organizacional e a escola da condição humana no trabalho.

Para Nadler e Lawer (1983), a QVT é a grande esperança das organizações para atingirem alto nível de produtividade, sem esquecer a motivação e satisfação do indivíduo. Hoje esse é um termo indispensável a toda empresa pelo fato de abranger o bem-estar físico, psicológico e social das pessoas que delas necessitam.

Fernandes (1996) diz que:

Qualidade de vida no trabalho pode ser utilizada para que as organizações renovem suas formas de organização no trabalho, de modo que, ao mesmo tempo em que se eleve o nível de satisfação do pessoal, se eleve também a produtividade das empresas, como resultados de maior participação dos empregados nos processos relacionados ao seu trabalho (p. 35).

França (2007) fala que existem oito critérios segundo Walton (1974) que podem auxiliar na compreensão da QVT: 
Compensação justa e adequada, condições de trabalho seguras e saudáveis, oportunidades imediatas para desenvolver e usar as capacidades humanas, oportunidades futuras para o crescimento contínuo e a garantia do emprego, interação social na organização, constitucionalismo na organização, trabalho e espaço total na vida do indivíduo, e relevância social no trabalho (p. 34).

Tais critérios, se utilizados, demonstram a qualidade nas empresas e motivam empregados. Segundo Maximiano (2004), as teorias da motivação preocupam-se predominantemente com a satisfação das pessoas. Portanto a QVT cuida do bem-estar geral e da saúde dos colaboradores, aumentando a produtividade nas empresas e fazendo com que as pessoas satisfaçam tanto as suas necessidades como também as da organização.

A Qualidade de Vida no Trabalho é peça fundamental para um bom desempenho nas organizações. Diz Chiavenato (2004, p. 448) que "a competitividade organizacional e obviamente, a qualidade e produtividade passam obrigatoriamente pela QVT. Para bem atender o cliente externo, a organização não deve esquecer o cliente interno".

Alguns Modelos para a QVT são:

a) Modelo de Westley (1979): demonstra os problemas que afetam a QVT, o político, o econômico, o psicológico e o sociológico. O problema político traria insegurança; o econômico, a injustiça; o psicológico, a alienação e o sociológico, a anomia.

b) Modelo de Hackman e Oldham (1975): modelo de QVT dedicado aos desenhos de cargos. As dimensões dos cargos conduzem a resultados que melhoram essa ferramenta. Sendo essas dimensões a Variedade de Habilidades, a Identidade da Tarefa, o Significado da Tarefa, a Autonomia, a Retroação do próprio trabalho, a Retroação extrínseca e o Inter-relacionamento. Os autores falam que tais dimensões são pontos fortes da QVT pelo fato de oferecerem recompensas que produzirão satisfação no cargo e trarão bons resultados no trabalho em si.

c) O Modelo de Wether e Davis (1983): analisa o projeto de cargos que são vistos pelos autores nos níveis organizacional, ambiental e comportamental. No organizacional aborda principalmente a eficiência; no nível ambiental, a habilidade e disponibilidade de empregados e as expectativas sociais. E o nível comportamental está ligado às necessidades de motivação e satisfação.

d) Modelo de Walton (1974): para Walton, existem oito fatores que afetam a QVT: Compensação Justa e Adequada; Condições de Segurança e Saúde no Trabalho; Utilização e desenvolvimento de capacidades; Oportunidade de crescimento contínuo e segurança; Integração social na organização; Constitucionalismo; Trabalho e esforço total de vida; Relevância Social da vida no trabalho. 


\section{METODOLOGIA}

O estudo foi desenvolvido na instituição de ensino superior CESAC, que é uma instituição mantenedora da FACRUZ e do ISED. O CESAC oferece os cursos de Administração de Empresas e Pedagogia. Tendo iniciado suas atividades no ano de 2005, é uma empresa que vem crescendo por meio de uma política de ensino e aprendizagem que preza pela qualidade na educação, estimulando seu aluno à formação de um senso crítico e de um caráter humanístico. A empresa possui 31 funcionários dos quais 21 são professores que lecionam nos cursos acadêmicos de administração e pedagogia.

No que se refere à operacionalização desta pesquisa, foram utilizadas as seguintes classificações:

Quanto aos meios optou-se por um estudo de caso. Para Yin (2001, p. 32) o estudo de caso “investiga um fenômeno contemporâneo dentro se seu contexto da vida real especialmente quando os limites entre o fenômeno e o contexto não estão claramente definidos".

No que tange à abordagem, esta pode ser classificada como de ordem quantitativa, pois é caracterizada pela quantificação dos dados. Segundo Roesch (2007, p. 130), a pesquisa quantitativa "implica em medir relações entre variáveis (associação causa e efeito), ou avaliar o resultado de algum sistema ou projeto".

Inicialmente foi necessária a realização de uma revisão bibliográfica para assimilação de conceitos.

Quanto aos fins, optou-se por uma pesquisa exploratória e descritiva. Roesch (2007, p. 137) diz que na pesquisa descritiva “o objetivo é obter informações sobre uma população”. Gil (2001b) define a pesquisa exploratória como aquela que possibilita ao pesquisador uma gama maior de conhecimento a respeito do tema ou problema objeto de pesquisa.

O universo em estudo nesta pesquisa são os docentes da instituição de ensino superior CESAC, 21 docentes. A população desta pesquisa foi circunscrita a 18 entrevistados, selecionados por acessibilidade, utilizando-se um questionário estruturado, para facilitar a coleta de informações e análise dos dados. O questionário foi construído a partir da metodologia de Walton (1974), que serve para verificação do nível de QVT abordando os oito critérios: compensação justa e adequada; condições de trabalho; oportunidade de uso e desenvolvimento de suas capacidades; oportunidades de crescimento e segurança; integração social no trabalho; constitucionalismo; trabalho e espaço total de vida e relevância social da vida no trabalho.

Revista de Administração e Inovação, São Paulo, v. 9, n. 2, p. 79-97, abril/jun. 2012. 
Para a realização da análise dos dados foram utilizadas as técnicas estatísticas de distribuição e frequência. Os dados foram obtidos através de um questionário composto por 35 questões que abordavam os oito critérios de Walton (1974) com a finalidade de observar o nível de QVT da empresa CESAC.

\section{APRESENTAÇÃO E ANÁLISE DOS RESULTADOS}

\subsection{Dados Sociodemográfico}

Constatou-se que $78 \%$ do corpo docente é composto por mulheres e $22 \%$ por pessoas do sexo masculino; observou-se que $44 \%$ tem entre 31 e 40 anos, $28 \%$ está acima de 41 anos e $28 \%$, entre 21 e 30 anos; verificou-se que $50 \%$ dos respondentes são solteiros, $11 \%$, divorciados e 39\%, casados; quanto à formação acadêmica, 50\% dos entrevistados têm especialização, 44\% mestrado, 6\% doutorado e $0 \%$ apenas graduação; quanto ao tempo na empresa $76 \%$, a maioria, dos professores trabalham de um a mais de três anos na instituição, o que mostra que a empresa tem um índice de rotatividade baixo, considerando que existe há quatro anos e os docentes continuam lecionando na organização; 94\% dos docentes do CESAC têm de um a três anos de tempo de atuação na área de ensino, os outros $6 \%$ tem mais de três anos na área.

\subsection{Qualidade de Vida no Trabalho}

Pelo modelo de Walton (1974) com seus oito critérios e seus respectivos indicadores, constatou-se:

\subsubsection{Critério I - Compensação justa e adequada}

a) Indicador: Renda Adequada ao trabalho: $60 \%$ acha média a adequação do salário as suas tarefas como professores, já $28 \%$ disse ser muito adequado e $12 \%$ respondeu pouco e nada adequado, ou seja, boa parte dos entrevistados acredita não receber um salário adequado; quanto aos benefícios extrassalariais 39\% dos respondentes afirmam não receber nenhum beneficio; $10 \%$ diz que raramente recebe; $17 \%$ que sempre recebe; $17 \%$ que quase sempre recebe e mais $17 \%$ que às vezes recebe. Isso demonstra que não existe beneficio extra, apenas o tíquete alimentação que é disposto aos professores. Nesse aspecto, no que diz respeito à questão de 
benefícios extrassalariais, a empresa perde ponto na percepção da QVT, pelo fato de apenas o tíquete alimentação de alguns professores ser a única forma de bônus salarial, considerando também que os docentes viajam aproximadamente 120 quilômetros de onde residem até onde exercem o magistério, o tíquete, ao invés do caráter de bônus, torna-se um sentimento de obrigação da empresa.

b) Indicadores Equidade Interna e Externa: com relação à Equidade Interna, a pesquisa mostra que $78 \%$ acha que não existe nenhuma diferença salarial, ou seja, a maioria percebeu que não existe muita diferença nas questões salariais da empresa, a diferença reside no fato de professores com mais horas-aula e com uma formação acadêmica mais avançada, ganham mais. Portanto é um ponto positivo na percepção da QVT da empresa e fator que pode estimular os professores a buscarem se qualificar mais para que assim possam ganhar mais. Já na Equidade Externa, os dados podem ser classificados como: $6 \%$ acha completamente justos, $28 \%$ muito justo, $11 \%$ acha pouco justo e $55 \%$ acha média a diferença. Observa-se que, quando indagados a respeito da equiparação salarial com as demais empresas do setor, os entrevistados na sua maioria não veem muita diferença, o que pode ser um ponto negativo na percepção da QVT da empresa.

\subsubsection{Critério II - Condições de trabalho}

a) Indicador Jornada de trabalho: constatou-se que na questão do tempo de trabalho para realização das tarefas, $61 \%$ respondeu que sempre ou quase sempre o tempo de trabalho é suficiente, no caso relacionado ao tempo que o professor está na sala de aula. Já no que diz respeito à jornada de trabalho, apenas $6 \%$ respondeu que quase sempre é cansativo, 55\% diz que às vezes a jornada é cansativa, $17 \%$ respondeu que raramente e $22 \%$ afirma que a jornada nunca é cansativa;

b) Indicador Ambiente Físico Seguro e Saudável: obteve-se ótimas respostas a respeito da organização, ventilação, higiene e iluminação do CESAC. No fator iluminação $50 \%$ diz ser ótima, já 39\% diz ser boa e apenas $11 \%$ que é razoável; o que denota a satisfação em relação à iluminação da empresa; tanto o fator ventilação quanto o fator higiene tiveram $78 \%$ das respostas como boa ou ótima, tendo apenas $22 \%$ das respostas como razoável; no ponto organização verifica-se que $72 \%$ afirmou que a empresa é bem administrada e apenas $28 \%$ disse que é razoável a performance da organização.

c) Ambiente Seguro: com relação à segurança do ambiente, apesar de 34\% dos questionados afirmar nunca ter visto nenhuma ferramenta de proteção da instituição, $44 \%$ sempre se sente 
seguro no ambiente de trabalho e $44 \%$ quase sempre se sente seguro, apenas $12 \%$ respondeu que às vezes ou raramente se sente seguro.

\subsubsection{Critério III - Oportunidade de uso e desenvolvimento de capacidades}

a) Indicador Autonomia: $28 \%$ dos pesquisados afirmou que sempre ou quase sempre tem autorização para decidir o que fazer no seu trabalho diário e $45 \%$ diz que às vezes conta com essa autonomia. Estes dados revelam que os entrevistados não estão presos a nenhuma autorização dos superiores, existe o respeito sim mas hoje se entende que a organização que deseja ser competitiva deve deixar de lado a centralização de decisões rotineiras e apostar na criatividade de seus empregados, despertando assim a autoconfiança nos indivíduos.

b) Indicadores: Significado da Tarefa e Identidade com a Tarefa. Estes indicadores revelaram resultados incrivelmente positivos, em que um total de $88 \%$ sente-se completamente ou muito importante com a atividade que realiza e $94 \%$ dos entrevistados disseram ser muito ou completamente felizes pelo trabalho que executam.

c) Indicadores: Variedade de habilidades e Retroinformação. Com relação ao fator Variedade de habilidades, as respostas foram totalmente positivas, $100 \%$ dos professores utilizam sempre ou quase sempre como ferramenta de trabalho seus conhecimentos e habilidades. Já a respeito da retroinformação verificou-se que $94 \%$ dos respondentes afirmaram serem sempre ou quase sempre avaliados; a pesquisa revela que a maioria entende que recebe esse tipo de informação da empresa. Pode-se entender o processo de feedback da seguinte forma: a Instituição de Ensino aplica todos os semestres um questionário autoavaliativo institucional que serve de subsídio para a melhoria contínua da instituição. É importante mencionar, ainda, que este se apresenta como ponto facilitador na implantação de melhorias nos processos e rotinas, pois os funcionários recebem retorno sobre seu trabalho e, assim, podem melhorar onde tiveram baixo desempenho.

\subsubsection{Critério IV - Oportunidade de crescimento e segurança}

a) Indicador: Possibilidade de Carreira. De acordo com os dados obtidos, constatou-se que os funcionários sentem não ter oportunidade de ascensão profissional, um total de $55 \%$ dos entrevistados veem a chance de se promover na empresa como pouca ou nenhuma; $28 \%$, como uma chance média e apenas $18 \%$ acreditam muito ou completamente nas chances de promoção.

b) Indicador: Crescimento Profissional. Nota-se na verificação do fator investimento em treinamento dos colaboradores que este não é muito destacado na empresa, em que 39\% 
disseram que o investimento é feito às vezes, $33 \%$ dos entrevistados disseram que é muito raro, $11 \%$ que sempre, mais $11 \%$ que quase sempre e $6 \%$ que nunca existiu investimento em treinamento. Quanto ao estímulo da empresa aos estudos dos funcionários, $72 \%$ afirmam que este está sempre, ou quase sempre presente, $6 \%$ disseram que às vezes sentem esse estímulo por parte da empresa e $24 \%$ raramente ou nunca perceberam esse estímulo.

c) Indicador: Segurança no emprego. Os resultados mostram que pelo fato de ser uma empresa que ainda está em seu início, com apenas quatro anos, não existe um número extensivo de turmas, e também só é feito um vestibular ao ano, os professores acabam demonstrando certa insegurança em sua permanência no emprego, assim, 44\% dos entrevistados disseram se sentir seguros às vezes, 6\% nunca se sentem seguros, 33\% quase sempre sentem segurança na permanência e apenas $17 \%$ sempre estão seguros.

\subsubsection{Critério V - Integração social no trabalho}

a) indicador: Relacionamento. Para a totalidade dos indivíduos entrevistados, o clima entre os colegas de trabalho é considerado entre bom e ótimo, o que possibilita um ambiente ideal para desenvolvimento do trabalho. Os resultados foram 55\% ótimo, 39\% bom e 6\% razoável.

b) Indicador: Igualdade de Oportunidade. Com relação ao desrespeito de superiores com funcionários, observa-se que $60 \%$ dos que responderam disseram que nunca foram desrespeitados de nenhuma forma, e o restante $28 \%$ que às vezes são, e $6 \%$ que raramente. Esse ponto é muito importante para a boa relação do gestor e seus liderados, o respeito à dignidade é um valor que deve ser prezado em toda e qualquer organização.

\subsubsection{Critério VI - Constitucionalismo}

a) Indicador: Respeito às leis trabalhistas. O público interno da empresa estudada, em sua totalidade acredita que os direitos trabalhistas constitucionais são sempre respeitados.

b) Indicador: Liberdade de expressão. Com $44 \%$ de respostas sempre e 33\% de quase sempre, infere-se que os funcionários sentem-se livres para contribuir com opiniões, podendo-se ainda incentivar um pouco mais esta prática para que os indivíduos que a realizam raramente ou às vezes sintam-se dispostos a contribuir mais.

c) Indicador: Normas e rotinas. Na questão de divulgação e debate de normas e rotinas, $43 \%$ disse que sempre são divulgadas, 39\% que quase sempre, ou seja, a maioria deu uma resposta positiva, sabe-se que a informação é algo fundamental para a sobrevivência de qualquer 
organização, além disso, a divulgação e o debate adequado e coerente de normas e rotinas possibilitam que muitos erros e enganos sejam evitados.

\subsubsection{Critério VII - Trabalho e espaço total de vida}

a) Indicador: Papel Balanceado no Trabalho. No fator Equilíbrio na vida pessoal e profissional grande parte dos entrevistados diz ter um equilíbrio, $6 \%$ disse que raramente e mais $6 \%$ que nunca, $22 \%$ disse que às vezes tem e $66 \%$ disse ter sempre ou quase sempre um bom equilíbrio na vida familiar e profissional, o que é um fator que é indispensável na vida de qualquer pessoa. Em relação a se o trabalho prejudica a vida familiar tem-se um resultado positivo também, em que $60 \%$ respondeu nunca ter sido prejudicado, o que é positivo para qualidade da vida dos colaboradores, existe um aproveitamento do trabalho e da família, 17\% afirmou que raramente foi prejudicado, $6 \%$ às vezes se sente prejudicado, $11 \%$ quase sempre e $6 \%$ sempre sente que o trabalho prejudica a vida familiar. No fator tempo para lazer, os dados mostram que $6 \%$ sempre tem tempo para o lazer, $26 \%$ quase sempre, $44 \%$ às vezes, $17 \%$ raramente e $6 \%$ nunca. Isso mostra que os professores são muito atarefados e se entregam ao trabalho, eliminando os momentos de lazer para fazer o trabalho com qualidade.

\subsubsection{Critério VIII - Relevância social da vida no trabalho}

a) Indicador: Imagem da Empresa. 56\% dos entrevistados se sentem completamente orgulhosos de dizer onde trabalham, e os demais $44 \%$ sentem-se muito orgulhosos. Esse pode ser considerado um ponto positivo, pois gera satisfação ao fazer parte da organização, e consequentemente na vontade de permanecer nela. Com relação à imagem da empresa junto à comunidade local, a maioria dos entrevistados entende que a empresa possui uma imagem respeitosa, este fator acaba por contribuir para o próprio sentimento de orgulho do funcionário em fazer parte da organização. Os resultados foram: $61 \%$ dizem ser bom, $33 \%$ que a imagem é ótima e $6 \%$ que é razoável. 


\begin{tabular}{|c|c|}
\hline Critérios & Indicadores \\
\hline 1- Compensação justa e adequada (+) & $\begin{array}{l}\text { Renda adequada ao trabalho }(+) \\
\text { Equidade interna }(+) \\
\text { Equidade externa }(-)\end{array}$ \\
\hline 2- Condição de trabalho (+) & $\begin{array}{l}\text { Jornada de trabalho }(+) \\
\text { Ambiente físico seguro e saudável }(+)\end{array}$ \\
\hline $\begin{array}{l}\text { 3- Oportunidade de uso e desenvolvimento de } \\
\text { capacidades (+) }\end{array}$ & $\begin{array}{l}\text { Autonomia (+) } \\
\text { Significado da tarefa }(+) \\
\text { Identidade da tarefa }(+) \\
\text { Variedade da habilidade }(+) \\
\text { Retroinformação }(+)\end{array}$ \\
\hline 4- Oportunidade de crescimento e segurança (-) & $\begin{array}{l}\text { Possibilidade de carreira (-) } \\
\text { Crescimento profissional (-) } \\
\text { Segurança de emprego (+) }\end{array}$ \\
\hline 5- Integração social no trabalho (+) & $\begin{array}{l}\text { Igualdade de oportunidade }(+) \\
\text { Relacionamento }(+)\end{array}$ \\
\hline 6- Constitucionalismo (+) & $\begin{array}{l}\text { Respeito às leis e direitos trabalhistas }(+) \\
\text { Liberdade de expressão }(+) \\
\text { Normas e rotinas }(+)\end{array}$ \\
\hline 7- Trabalho e espaço total da vida (+) & Papel balanceado do trabalho $(+)$ \\
\hline 8- Relevância social da vida no trabalho (+) & Imagem da empresa (+) \\
\hline
\end{tabular}

Quadro 1: Resumo dos resultados obtidos na pesquisa.

Fonte: Elaborado pelos autores.

No Quadro 1 pode-se ver que os resultados do nível de QVT da empresa em estudo é positivo, sendo assim, a Faculdade CESAC proporciona a seus docentes um bem-estar no que se refere ao trabalho, fazendo com que eles se sintam cada vez mais estimulados e motivados a trabalharem da melhor maneira possível, buscando sempre a melhoria contínua.

\section{CONSIDERAÇÕES FINAIS}

O estudo abordou o assunto QVT, tema que vem sendo amplamente discutido entre empresas, trabalhadores e consumidores.

O estudo se deu a partir do modelo de Walton (1974) e seus oito critérios. A pesquisa buscou averiguar a satisfação dos funcionários para cada um desses critérios, verificando se eles são ou não compatíveis com as expectativas. Com as respostas e dados obtidos na pesquisa, pode-se constatar que o nível de QVT da Faculdade CESAC - Santa Cruz do Capibaribe - PE, a partir das respostas do corpo docente da empresa, é positivo, por possuir um grande número de respostas que comprovam a qualidade. 
Quanto ao critério compensação justa e adequada, verificou-se que os funcionários em sua maioria estão satisfeitos, o que eleva a qualidade do trabalho tornando-os mais motivados. A empresa deve continuar mantendo esse padrão de remuneração para que sempre possa atingir as expectativas de seu empregado.

Quanto ao critério condições de trabalho, o conforto e segurança que o trabalho deve proporcionar ao colaborador é indispensável para a busca da qualidade de vida no trabalho, com isso é indispensável que a organização busque aperfeiçoar suas condições de trabalho. Os resultados obtidos quanto a esse critério foram positivos, o que eleva a percepção e satisfação dos clientes internos na faculdade CESAC.

Quanto ao critério oportunidade de uso e desenvolvimento de capacidades, todos os entrevistados encontram-se satisfeitos, o que é muito importante e quantitativo para a empresa, a partir do momento que os profissionais usam da melhor forma possível os indicadores que, no caso, são autonomia, significado da tarefa, identidade da tarefa, variedade de habilidades, retroinformação, passam ao cliente confiabilidade e satisfação gerando a qualidade no serviço e por fim a QVT desejada.

Quanto ao critério oportunidade de crescimento e segurança, não se obteve um resultado positivo em todos os indicadores, apenas no fator segurança no emprego, mas vale ressaltar que na empresa não existe nenhum cargo maior que os professores poderiam exercer, o crescimento seria relativo apenas ao valor do salário que poderia aumentar de acordo com o grau de formação profissional, então não tem como galgar cargos, pois não existe nenhum cargo superior para o crescimento dentro da empresa.

Quanto ao critério integração social no trabalho, é também ponto positivo dentro da empresa, pois os dados mostram que existe um ótimo relacionamento dentro do estabelecimento, o que potencializa a QVT pelo fato de que onde se trabalha com pessoas que se respeitam, que se dão bem, têm-se melhor desempenho e satisfação dos clientes externos e dos parceiros da organização.

Quanto ao critério constitucionalismo, avalia-se que a empresa se preocupa em cumprir os direitos e deveres trabalhistas, bem como em propiciar um ambiente onde haja liberdade de expressão, constituindo fatores positivos à QVT, além disso, se preocupa em divulgar e debater suas normas e rotinas entre todos da organização, pois a falta desse procedimento influencia negativamente no desempenho do trabalhador.

Quanto ao critério trabalho e espaço de vida, verificou-se haver entre os funcionários equilíbrio entre trabalho e vida familiar, e a maioria se encontra satisfeita. Todavia, é preciso que a 
empresa trabalhe de forma a propiciar um equilíbrio, para que assim ela alcance um ambiente de trabalho cada vez mais saudável, equilibrado, e com maior rendimento.

Quanto ao critério relevância social da vida no trabalho, faz-se uma análise positiva já que os trabalhadores se sentem orgulhosos em fazer parte da organização e reconhecem que a empresa tem uma respeitosa imagem na comunidade local.

Quanto às dificuldades apresentadas, nota-se que o CESAC não dispõe de equipamentos de segurança, fato que prejudica a qualidade da organização e atrapalha a imagem de segurança que será passada a todos os usuários dos serviços da empresa.

Portanto, com base nos resultados obtidos com o estudo, propõe-se que a faculdade: busque sempre melhorias salariais, para obtenção de satisfação contínua de seu empregado; estude a possibilidade de conceder aos profissionais benefícios extrassalariais, como assistência médica e odontológica, e não apenas alimentação; dê importância à utilização de técnicas e equipamentos de segurança; melhore cada vez mais o ambiente físico da empresa; invista em capacitação; continue dando e recebendo feedback, para um melhor desempenho e correção de erros; busque continuar sempre proporcionando um bom relacionamento entre todos; estude a possibilidade de providenciar uma área de lazer para os funcionários; invista em propaganda para divulgar o nome da empresa.

A empresa também precisa trabalhar de forma a mostrar a importância que os funcionários têm para a organização. O objetivo é que as pessoas sintam-se importantes e desse modo motivadas para buscarem melhoria contínua do serviço prestado, e assim alcançarem a QVT desejada.

\section{REFERÊNCIAS}

Araujo, L. C. G. (2006). Gestão de pessoas. São Paulo: Atlas.

Castiglione, J. A. M. (2006). Assistente administrativo. São Paulo: Erica.

Chiavenato, I. (2002) Administração de recursos humanos: fundamentos básicos. São Paulo: Atlas.

Chiavenato, I. (2004). Gestão de pessoas: o novo papel dos recursos humanos nas organizações. Rio de Janeiro: Elsevier.

Fernandes, E. C. (1996). Qualidade de vida no trabalho: como medir para melhorar. Salvador: Casa da Qualidade.

França, A. C. L. (2007). Qualidade de vida no trabalho - QVT: conceitos e práticas nas empresas da sociedade pós-industrial (2a ed.). São Paulo: Atlas.

Gil, A. C. (2001a). Como elaborar projetos de pesquisa (3a ed.). São Paulo: Atlas.

Revista de Administração e Inovação, São Paulo, v. 9, n. 2, p. 79-97, abril/jun. 2012. 
Gil, A. C. (2001b). Gestão de pessoas: enfoque nos papeis profissionais. São Paulo: Atlas.

Hackman, J. R., \& Oldhan, G. R. (1975). Development of the job diagnostic survey. Journal of Applied Psychology, 60(2), 159-170.

Maximiano, A. C. A. (2004). Introdução a administração. São Paulo: Atlas.

Moller, C. O lado humano da qualidade: maximizando a qualidade de produtos e serviços através do desenvolvimento das pessoas. São Paulo: Pioneira.

Nadler, D. A., \& Lawer, E. E. (1983). Comportamento organizacional. Rio de Janeiro: Campus.

Rodrigues, M. V. (2007). Qualidade de vida no trabalho: evolução e análise gerencial. Rio de Janeiro: Vozes.

Roesch, S. M. A. (2007). Projetos de estágio e de pesquisa em administração (3a ed.). São Paulo: Atlas.

Rossi, A. M., Parrewé, P. L., \& Saunter, S. L. (2007). Stress e qualidade de vida no trabalho: perspectivas atuais da saúde ocupacional São Paulo: Atlas.

Walton, R. E. (1974). Improving the quality of work life. Harvard Business Review, 12(155), 12-16.

Westley, W. A. (1979). A qualidade de vida no trabalho: problemas e soluçoes. Rio de Janeiro: Incisa.

Werther, W., Jr., \& Davis, K. (1983). Administração de pessoal e recursos humanos. São Paulo: McGraw Hill.

Yin, R. K. (2001). Estudo de caso: planejamento e métodos (D. Grassi, Trad.) (2a ed.). Porto Alegre: Bookman. 


\title{
QUALITY OF WORKING LIFE OF TEACHING: A CASE STUDY AT AN HIGHER EDUCATION INSTITUTION
}

\begin{abstract}
In a world increasingly globalized and competitive, the organizations have on the people your largest difference. And then appear the willingness of officials to have the quality of work life, looking for the best way in obtaining a better organizational performance. This paper aimed to examine aspects relating to Quality of Life of yours teachers that make up faculty Centre for Higher Education Santa Cruz (CESAC), mantenedoura FACRUZ - College of Santa Cruz and the Institute of Education - ised in the Santa Cruz Capibaribe - PE. The chosen theoretical model for the study was to evaluate the Quality of Working Life of Richard Walton, this model is composed by eight criteria, each with yours respective indicators. For each of the criteria of the model, the research sought to observe whether the questions were related to the desires and expectations of employees. On the methodology we opted for an exploratory and descriptive study. The data collection was a structured questionnaire and that was administered to teachers of the company. It was observed that the level of employee satisfaction was higher, which demonstrates the existence of indicators of Quality of Working Life in the company.
\end{abstract}

Key-Words: Quality of working life; Performance; Satisfaction.

\section{Agradecimentos}

Os autores agradecem o apoio da Coordenação de Aperfeiçoamento de Pessoal de Nível Superior CAPES.

Data do recebimento do artigo: 15/09/2011

Data do aceite de publicação: 26/01/2012 